\title{
What to do when the acute type A aortic dissection involves the aortic sinuses
}

\author{
Tirone E. David, MD
}

\author{
From the Division of Cardiovascular Surgery of the Peter Munk Cardiac Centre at Toronto General Hospital and \\ University of Toronto, Toronto, Ontario, Canada. \\ Disclosures: Author has nothing to disclose with regard to commercial support. \\ Received for publication June 24, 2018; revisions received June 24, 2018; accepted for publication June 25, 2018; \\ available ahead of print Aug 7, 2018. \\ Address for reprints: Tirone E. David, MD, 200 Elizabeth St, 4N453, Toronto, Ontario M5G 2C4, Canada (E-mail: \\ tirone.david@uhn.ca). \\ J Thorac Cardiovasc Surg 2018;156:2083 \\ $0022-5223 / \$ 36.00$ \\ Copyright (c) 2018 by The American Association for Thoracic Surgery \\ https://doi.org/10.1016/j.jtcvs.2018.06.072
}

In this issue of the Journal, Sievers and colleagues ${ }^{1}$ from Lübeck, Germany, report their examination of the results of surgery for acute type A aortic dissection with involvement of the aortic root in patients in whom the aortic root was preserved by means of reimplantation of the aortic valve (44 patients, mean age of 56.9 years, mean followup of 15.8 years); remodeling of the aortic root with replacement of 1,2 , or all 3 aortic sinuses (39 patients, mean age of 62.6 years, mean follow-up of 11.8 years); and repair of the dissected root with polytetrafluoroethylene felt with or without biologic glue (96 patients, mean age of 64.5 years, mean follow-up of 9.3 years). Sievers and colleagues ${ }^{1}$ found similar long-term outcomes for all groups with respect to survival and reoperation rates. They therefore concluded that less is as good as more; that is, root repair provided similar results to those seen with a more complex and extensive procedure, such as reimplantation of the aortic valve. Given the relatively small sample sizes of the subgroups, the high operative mortality associated with surgery for acute type A aortic dissection, and the differences in duration of follow-up, one has to take the interpretation of the results with caution, particularly the multivariable analyses of risk factors associated with survival (Table 3 in the article of Sievers and colleagues ${ }^{1}$ ).

As I have mentioned in previous writings on acute type A aortic dissection, surgery for this aortic catastrophe is often done by general cardiac surgeons who may not be familiar with such complex operative procedures as aortic valvesparing operations, and for them the preservation of the aortic root with polytetrafluorethylene felt and biologic glue is probably the safer procedure, since the main goal of this surgery is to save the patient's life. ${ }^{2}$ Not only is this approach probably safer than a more complex procedure to save the aortic root, Sievers and colleagues ${ }^{1}$ now have provided data to indicate that it may be a preferable approach. Obviously, if the aortic cusps are diseased, aortic valve replacement with or without replacement of the aortic root is necessary.

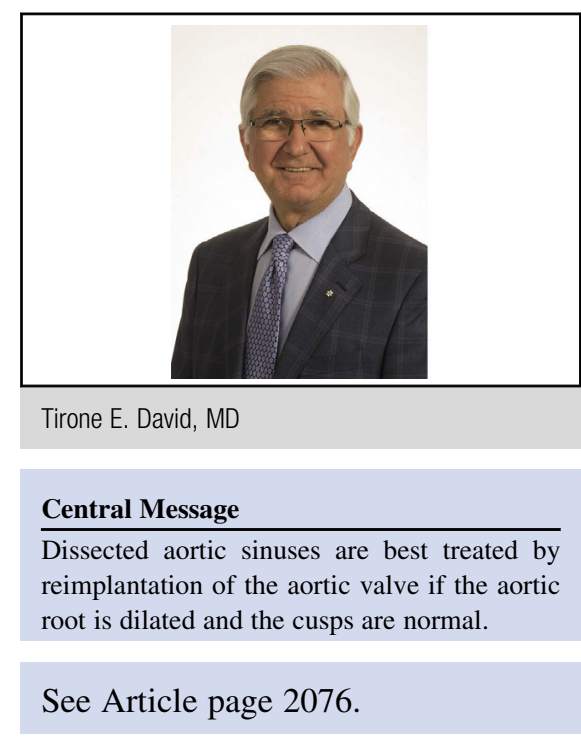

Experienced aortic surgeons should deal with the acutely dissected aortic root as they do in elective cases and match the operative procedure to the aortic root pathology. Aortic valves with normal cusps or cusps with mild and easily correctable abnormalities should be preserved, regardless of how extensively the dissection involves the aortic sinuses. I believe that older patients (eg, $>60$ years of age) with a normal aortic annulus (eg, $<25 \mathrm{~mm}$ in diameter) should have remodeling of the aortic root performed if only 1 aortic sinus is dissected. A tubular Dacron polyester fabric graft of diameter equal to the sinotubular junction can be tailored to replace the supracoronary ascending aorta and the dissected aortic sinus. ${ }^{3}$ If the dissection does not extend down to the aortoventricular junction, a more conservative approach with fibrin glue and external polytetrafluoroethylene felt reinforcement is adequate. Extensive dissection of 2 or 3 aortic sinuses is best treated with reimplantation of the aortic valve, because this provides a more hemostatic and durable reconstruction of the aortic root. Younger patients (eg, <60 years of age), patients with a dilated aortic annulus (eg, $>25 \mathrm{~mm}$ in diameter) are best treated with reimplantation of the aortic valve.

\section{References}

1. Sievers HH, Richardt D, Diwoky M, Auer C, Bucsky B, Nasseri B, et al. Surviva and reoperation after valve-sparing root replacement and root repair in acute type A dissection. J Thorac Cardiovasc Surg. 2018;156:2076-82.e2.

2. David TE. Surgery for acute type A aortic dissection. J Thorac Cardiovasc Surg. 2015;150:279-83.

3. David TE. Aortic valve sparing in different aortic valve and aortic root conditions J Am Coll Cardiol. 2016;68:654-64. 